\title{
Quality Traits of Fillet of Gilthead Sea Bream (Sparus aurata L.) of Two Market Sizes Reared according to an "Antibiotic-Free" Approach
}

\author{
A. Roncarati $(\mathbb{D}$, M. C. T. Meligrana $\mathbb{D}$, F. Laus $\mathbb{D}$, and A. Spaterna \\ School of Biosciences and Veterinary Medicine, University of Camerino, Viale Circonvallazione 93-95, 62024 Matelica, Italy \\ Correspondence should be addressed to A. Roncarati; alessandra.roncarati@unicam.it
}

Received 13 April 2019; Accepted 21 May 2019; Published 24 July 2019

Academic Editor: Fabio Napolitano

Copyright (c) 2019 A. Roncarati et al. This is an open access article distributed under the Creative Commons Attribution License, which permits unrestricted use, distribution, and reproduction in any medium, provided the original work is properly cited.

\begin{abstract}
Rearing of "antibiotic-free" fish is becoming one of the most important goals to be achieved in the near future. Strategies are going to be adopted to increase nonspecific immune system and biosecurity in fish farming. To show the quality traits of gilthead sea breams reared under a prescription of "antibiotic-free" (ABF), two different market sizes ( $R$ : about $350 \mathrm{~g}$ and $M$ : about $490 \mathrm{~g})$ were analysed at the end of the farming cycle performed in a floating cage plant in the Adriatic sea, in the Gulf of Valona (Albania). Proximate composition and fatty acid profile were determined in April and June 2018. The omega-3 content demonstrated that the ABF samples collected according to the fish size and the harvest month can be defined as "rich in omega-3," in compliance with the Annex to the Regulation (EC) n. 1924/2006, with a trend to increase in relation to fish growth.
\end{abstract}

\section{Introduction}

In the past, antimicrobials were used in food-producing animals to treat and control bacterial infections in the presence of disease, such as for disease prevention and growth promotion in the absence of disease [1]. In the last decade, it has been ascertained that the antimicrobial use in food-producing animals can lead to selection and dissemination of antimicrobial-resistant bacteria in these animals, which can then be transmitted to humans via food [2]. In recent years, the topic of antimicrobial resistance has become a priority at the international level. Nowadays, the FAO and the World Organization for Animal Health are adopting resolutions for public health promoting the global action plan, recognized as a "One Health" approach, to control the pressing problem posed by antimicrobial resistance. The prudent use of antimicrobials in human and veterinary medicine is considered a key element of the action plan in order to contain resistance bacteria for the benefit of both animal and human health.
The European Medicine Agency (EMA) and the European Food Safety Authority (EFSA) Joint Scientific Opinion (2017) on the use of antimicrobials claim that antibiotics are mostly used as metaphylactic treatment during the critical phases of the production cycle in aquaculture. In 2008, the European Platform for the Responsible Use of Medicines in Animals (EPRUMA) focalized a best-practice framework for the use of antibiotics in food-producing animals and, recently, published the building blocks which can be used to form a farm-specific health plan [3]. They suggested that the risks related to animal disease, contamination, or survival of biological hazards during aquatic farming can be controlled by applying prescriptions of "Good Manufacturing Practice" (GMP). In this situation, researchers and farmers are beginning to consider the use of feed additives, such as natural pre- and probiotics, vegetable sources, and other supplements that can enhance growth performances of aquatic organisms in farming conditions [2]. In many cases, these compounds are approved for food use by international organisms, such as the American Food and Drug Administration (FDA). An example of the most studied compounds 
among these phytogenic categories is represented by essential oils, known for their immunostimulant and antiinflammatory properties [4-6].

Moreover, also other compounds, produced by organic materials of plants, are used for antimicrobial, anti-inflammatory, and immunostimulatory effects through microbial activity due to their significant free radical scavenging properties [7]. Another strategy is aimed at increasing biosafety and biosecurity to prevent the access of pathogens and minimizing the risk of introducing diseases in fish farming.

Considering that the possibility of rearing "antibioticfree" fish is one of the most important goals to be achieved in the near future, we decided to monitor the fillet quality (proximate composition and fatty acid profile) of gilthead sea breams of two different market sizes, at the end of the farming cycle in floating cages, performed following a prescription of "antibiotic-free."

\section{Materials and Methods}

2.1. Fish Employed and Description of Rearing Technique. In order to analyse the fillet quality, in April and June 2018, sampling sessions of gilthead sea breams (ABF) of two different market sizes ( $R: 350 \pm 20 \mathrm{~g}$ and $M: 490 \pm 30 \mathrm{~g}$ ) were carried out from a plant located in the Gulf of Valona, Albania $\left(40^{\circ} 20^{\prime} 31.64^{\prime \prime} \mathrm{N}-19^{\circ} 25^{\prime} 18.05^{\prime \prime} \mathrm{E}\right)$. The farm applied an "Antibiotic-free Code of Prescription" to guarantee the quality of the product and respect the "antibiotic-free" approach. For this purpose, monthly samples of sea breams reared in all the cages were performed to show eventual antibiotic residues in the muscle. In particular, amoxicillin, flumequine, sulfadiazine, trimethoprim, oxytetracycline, and florfenicol were investigated by a certification authority (DNV GL, Germany). No residues were found in the muscles of the sea breams sampled in the plant.

The farm was composed of 20 circular floating HighDensity Polyethylene (HDPE) cages (diameter: $30 \mathrm{~m}$; depth: $15 \mathrm{~m}$ ) arranged in two parallel lines of 10 cages each. The useful capacity of each net was $10,600 \mathrm{~m}^{3}$, with a total production volume of $214,600 \mathrm{~m}^{3}$. In this area, there were strong freshwater currents which rose up from the bed and flowed into the seawaters. In this cage plant, the growing phase started at the fingerling stage, weighing 30-40 g, which reached market size (350-450 g) in about 14-16 months. Fingerlings exhibited high quality standards and were supplied by an Italian hatchery certified Global Good Agricultural Practices (G.A.P.) which obliged to total respect of the requirements of this international standard. In order to avoid stress due to inadequate manipulation, the transfer of the fingerlings takes place without removing them from the water, via pipelines that release the fish directly from the transport tanks, set up on the boat, to the breeding cages.

Low stocking density (around $15 \mathrm{~kg} / \mathrm{m}^{3}$ ) was adopted. In these conditions, and throughout the production cycle, the fish were not submitted to grading or manipulation. The cleaning of the nets was regularly performed using a system consisting of high-pressure pumps, which activated disks arranged vertically in two overlapping rows, using only high- pressure seawater. The adequate mesh size and the regular replacement, according to fish body growth, promoted adequate water circulation inside the cages. The modern and innovative fibre of nets of the rearing cages considerably reduced the net damage, avoiding the risk of fish escaping. Moreover, this type of net was designed to limit and control the development of fouling and the deposit of concretions, algae, and microorganisms. In this way, there was no use of antifouling substances and, therefore, polluting elements, such as heavy metals, were not released into the marine environment.

The personnel involved in fish farming and surveillance activities were trained to apply the practical guidelines contemplated in the animal welfare legislation. Divers were daily involved to check the integrity of mesh and cages.

The feed administration took place by means of a selfpropelled device that distributed the food directly onto the cage several times a day. The feed was transported from the production plant to the cage farm using only the company's big bags, in order to avoid any contamination. In the last 120 days of the rearing cycle, sea breams received a finisher diet (extruded feed) including fish meal, fish oil with contents of minimum $45 \%$ protein and $20 \%$ lipid, as wet weight basis, and essential oils extracted by oregano (Origanum vulgaris). Feed administration amounted at a daily ratio ranging between 0.8 and $1.2 \%$ of body weight, also depending on water temperature. During the sampling sessions, water quality was monitored, determining the main physicochemical parameters.

2.2. Morphobiometric Parameters and Indices. After fish were captured, sea breams were stored in tanks with seawater ice and transferred to the laboratory by portable coolers containing ice. In the laboratory, each fish was weighed to the nearest $0.1 \mathrm{~g}$ fresh weight with an electronic balance (Mettler Toledo mod. 5000), and the total body length (from the most anterior extremity to the tip of the caudal fin) was measured to the nearest millimetre using an ictiometer.

Body weight was measured using an electronic scale (Mettler 5000 Toledo, Thornton Inc., USA). The condition index $\left((\mathrm{KI})=\left((100 \times\right.\right.$ fish weight $) /$ fish length $\left.\left.{ }^{3}\right)\right)$ was calculated. The fish were eviscerated, and the viscerosomatic index $(($ VSI $)=($ viscera weight/whole body weight $) \times 100)$, the perivisceral fat index $((\mathrm{PFI})=($ perivisceral fat $/$ body weight $) \times 100)$, and hepatosomatic index $((\mathrm{HSI})=($ liver weight/body weight $\times 100$ ) were calculated. In order to measure the PFI and the VSI, the fat adherent to the digestive tract was accurately separated and individually weighed.

2.3. Chemical Composition and Fatty Acid Profile of the Fish Fillet. A portion of about $50 \mathrm{~g}$ of skinless dorsal muscle was collected from a pool of the specimens, sampled per group per time sampling ( $R$-April, $M$-April, $R$-June, and $M$-June), homogenised, and subjected to proximate analysis (moisture, protein, lipid, and ash content). The percentage of moisture was determined in duplicate according to the AOAC procedure (1990). The protein content was determined using 
the standard Kjeldahl copper catalyst method. The ash content was determined using the procedure described by the AOAC [8]. Total lipids were measured using a modification of the chloroform : methanol procedure described by Folch et al. [9]. After determining the total lipid content, fatty acids were converted to methyl esters following the method described by Christopherson and Glass [10]. The separation of fatty acids was performed using a Carlo Erba HRGC 5160 gas chromatograph (Carlo Erba Strumentazione, Rodano, MI, Italy) with a WP-4 Shimadzu integration system (Shimadzu Corporation, Tokyo, Japan) equipped with a Supelco SPTM-2340 capillary column $(30 \mathrm{~m} \times 0.32 \mathrm{~mm}$ i.d.; $0.20 \mu \mathrm{m}$ film thickness; Supelco, Bellefonte, PA, USA) and a flame ionization detector. The operating conditions of the gas chromatograph were as follows: the oven temperature was set at $170^{\circ} \mathrm{C}$ for $15 \mathrm{~min}$ and subsequently increased to $190^{\circ} \mathrm{C}$ at a rate of $1^{\circ} \mathrm{C} / \mathrm{min}$, then increased to $220^{\circ} \mathrm{C}$ at a rate of $5^{\circ} \mathrm{C} / \mathrm{min}$ and held at this temperature for $17 \mathrm{~min}$. The concentration of individual fatty acid was calculated based on the relative proportion of each fatty acid compared with a known amount of the internal standard $(17: 0)$ added. The fatty acids were expressed as $\mathrm{g} / 100 \mathrm{~g}$ of fillet.

2.4. Statistical Analysis. Data concerning quality traits were submitted to two-way analysis of variance (ANOVA) using SPSS 25 [11] considering the fish size (Si: $R$ and $M$ ) and the harvest month (mo: April and June) and their interaction as fixed effects. Differences were considered significant at $P<0.01$, and means were compared using the StudentNewman-Keuls (SNK) test.

\section{Results}

During the sampling sessions, water salinity ranged around $37 \pm 1 \mathrm{ppt} ; \mathrm{pH}$ was around 7.00 ; the dissolved oxygen was recorded at $7.58 \pm 0.5 \mathrm{mg} / \mathrm{l}$; the nitrogen compounds determined were ammonia $0.013 \pm 0.02 \mathrm{mg} / \mathrm{l}$, nitrites $0.057 \pm 0.01 \mathrm{mg} / \mathrm{l}$, and nitrates $0.50 \mathrm{mg} / \mathrm{l}$. Phosphates were recorded at $0.095 \pm 0.1 \mathrm{mg} / \mathrm{l}$.

Mean body weight, body length, and morphometric indices of the two groups of ABF- $R$ and ABF- $M$ sampled in the two sampling months (April and June) are reported in Table 1. The mean size, in terms of body weight and total length, was very similar between the sampling months within the market size, ABF- $R$ and ABF- $M$. With regard to morphometric indices, the PFI, VSI, and HSI did not show significant differences, and no notable difference was observed in the morphometric parameters between the $A B F$ sea breams.

In Table 2, the proximate composition showed significant differences $(P<0.01)$ in the lipid content both in terms of fish size, with low content in $R$ size (1.15\%) respect to $M$ size (1.4\%), and in terms of harvest month with the lowest level in April (0.85\%) compared to June sample (1.7\%).

The protein content did not show significant differences. The ash content exhibited no differences among the ABF fish.

Table 3 shows the data regarding the fatty acid profile of the fillets according to the fish size and the harvest time, which showed significant differences among the ABF fish. With regard to the saturated fatty acids (SFAs), the most important fatty acid was represented by palmitic acid (C16: 0 ) in all the samples. The MUFAs showed the same trend with a high level in all the groups. The $n-6$ PUFAs were more contained in the ABF June group. The $n-3$ PUFAs were mainly represented in the $M$ size sample respect to the $R$ sample. Among the fatty acids of this category, the most important were EPA and DHA in all the ABF fish, with very high contents in all the sampled fish.

\section{Discussion}

In this paper, we paid attention to rearing techniques and feeding to obtain favourable effects on the health of fish that can thus be farmed without the use of antibiotic compounds. The strict code of prescriptions indicated that the farming conditions were suitable for a rearing practice that aimed to prevent diseases. The physicochemical water parameters remained within the range suitable for gilthead sea bream [12] and showed high quality of environment characterized by strong sea currents that submitted fish to constant movement.

The sea bream were raised in high-volume cages, where there was plenty of space available and where densities were continuously monitored in relation to size. With regard to the morphometric parameters and somatic indices, the mean length and KI of the ABF fish showed no notable differences among the four groups. In a study carried out by Rodríguez et al. [13], captive black sea bream (Spondyliosoma cantharus, L.) achieved significant mesenteric and visceral lipid deposition compared to the wild fish. In addition, farmed gilthead sea bream fed diets including vegetable oil (soybean oil and linseed oil) in substitution of fish oil exhibited lower HSI than the control fish [14]. On the contrary, no differences emerged in sea bass fed diets containing freeze-dried microalgae as a partial substitution of protein and lipid from fish derivatives [15]. Recent studies have shown that the substitution of fish oil up to $60 \%$ with vegetable oil did not affect the growth and health status of European sea bass and gilthead sea bream [16].

In the present trial, the $\mathrm{ABF}$ sea bream displayed a very low lipid fraction which classified them in the category of lean fish. This result differed significantly from that reported in a trial performed in the Tyrrhenian Sea, which compared organic or conventional sea bream, reared in circular floating cages, at a stocking density similar to that adopted for ABF sea breams, analysed in this paper $\left(15 \mathrm{~kg} / \mathrm{m}^{3}\right)$ [17]. In fact, the conventional and organic sea bream showed total lipid content $(8.37 \pm 1.0$ and $9.52 \pm 1.8 \mathrm{~g} / 100 \mathrm{~g}$, respectively) higher compared to the $\mathrm{ABF}$ fish in our study.

It is well known that in fish, as in other animals of zootechnical interest, the feed affects the quality of the meat. The $\mathrm{ABF}$ sea breams were reared using feed containing raw materials of aquatic origin (fish meal and fish oil), which constituted the main source of omega- 3 series fatty acids, and also feedstuffs of vegetable origin in full respect of environmental sustainability. Data concerning the omega-3 content demonstrated that the $\mathrm{ABF}$ samples collected in 
TABLE 1: Body weight, total length, and morphometric indices of the ABF sea bream sampled at different market sizes $(R$ and $M)$ and month (April and June).

\begin{tabular}{|c|c|c|c|c|}
\hline & ABF-R-April & ABF-M-April & ABF-R-June & ABF-M-June \\
\hline Body weight (g) & $350.54 \pm 11$ & $490.64 \pm 16$ & $359.99 \pm 12$ & $498.25 \pm 14$ \\
\hline Total length $(\mathrm{cm})$ & $28.80 \pm 1.4$ & $29.71 \pm 1.2$ & $28.56 \pm 1.3$ & $30.25 \pm 1.4$ \\
\hline Condition index (KI) & $1.47 \pm 0.03$ & $1.87 \pm 0.01$ & $1.55 \pm 0.03$ & $1.8 \pm 0.05$ \\
\hline Perivisceral fat index (PFI) & $0.5 \pm 0.01$ & $0.4 \pm 0.01$ & $0.4 \pm 0.02$ & $0.5 \pm 0.02$ \\
\hline Viscerosomatic index (VSI) & $8.93 \pm 0.5$ & $8.96 \pm 0.4$ & $8.86 \pm 0.5$ & $9.25 \pm 0.6$ \\
\hline Hepatosomatic index (HSI) & $1.93 \pm 0.07$ & $1.58 \pm 0.08$ & $1.92 \pm 0.06$ & $1.66 \pm 0.07$ \\
\hline
\end{tabular}

TABle 2: Proximate composition (\% wet weight basis) of fillet of ABF gilthead sea bream according to fish size and harvest month.

\begin{tabular}{lcccccccc}
\hline & \multicolumn{2}{c}{ Fish size $(\mathrm{Si})$} & \multicolumn{2}{c}{ Harvest month (Mo) } & \multicolumn{2}{c}{$P$ value } \\
& $R$ & $M$ & April & June & MSE & Si & Mo & Si $\times$ Mo \\
\hline Moisture & 74.8 & 74.5 & 74.4 & 74.9 & 0.030 & 0.064 & 0.082 \\
Protein & 20.95 & 21.95 & 21.85 & 21.05 & 0.050 & 0.075 & 0.061 \\
Lipids & $1.15 \mathrm{~B}$ & $1.4 \mathrm{~A}$ & $0.85 \mathrm{~B}$ & $1.7 \mathrm{~A}$ & 0.002 & $*$ & 0.077 \\
Ash & 1.39 & 1.42 & 1.44 & 1.37 & 0.034 & 0.008 & 0.033 & 0.053 \\
\hline
\end{tabular}

A, B: $P<0.01 .{ }^{*}$ Significant.

TABLE 3: Fatty acid profile (mg/100 g flesh) determined in the fillet of ABF gilthead sea bream according to fish size and harvest month.

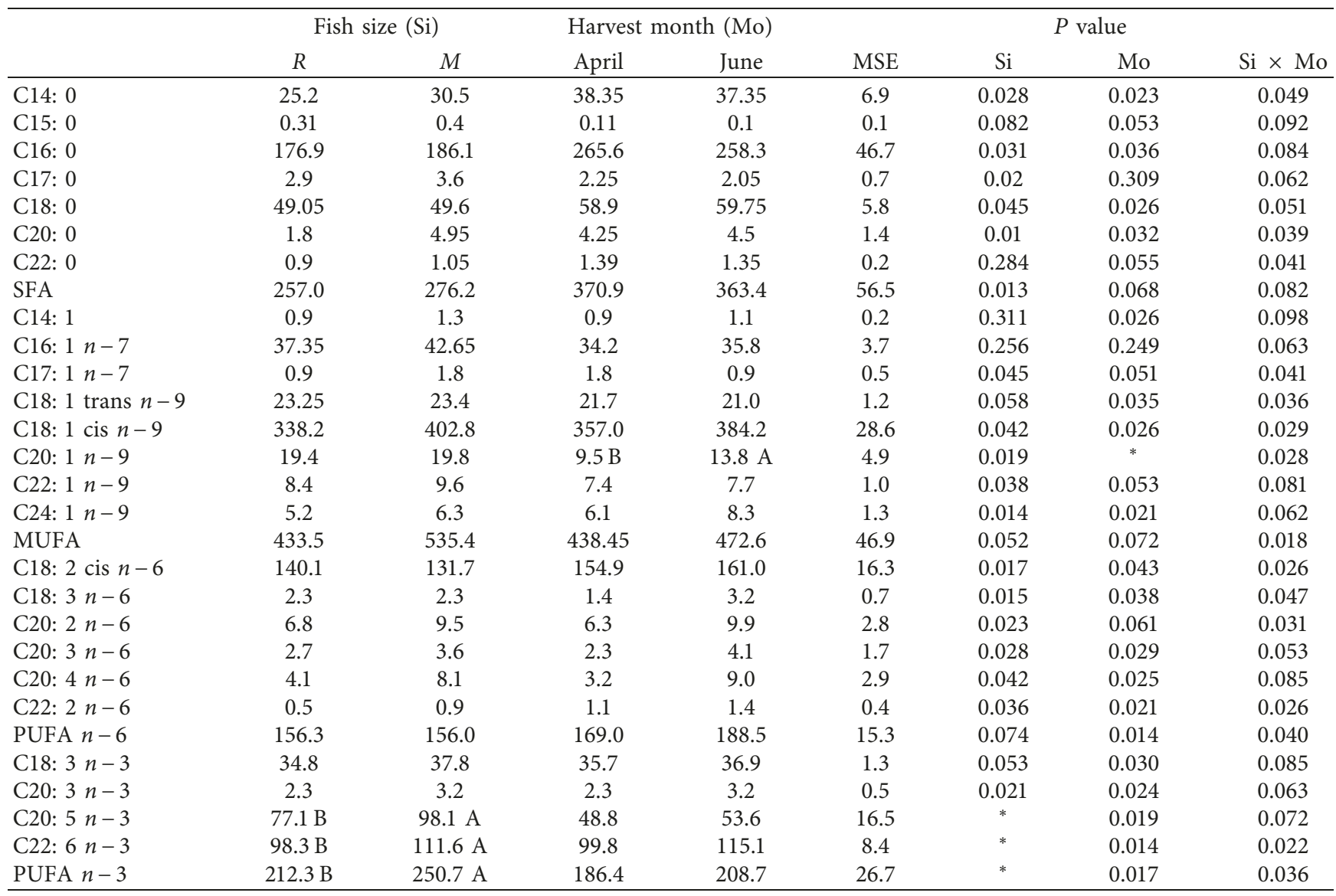

A, B: $P<0.01 ;{ }^{*}$ significant.

April and June can be defined as "rich in omega-3," in full compliance with the provisions of the Annex to the Regulation (EC) n. 1924/2006 on nutrition and health claims concerning food. We also noticed that in the sea breams analysed, omega-3 fatty acids increased with fish body size in both April and June. In another fish species, fish length 
appeared to play a role in fillet EPA and DHA accumulation, ascertaining that larger fish were able to store more lipids than the smaller ones $[18,19]$. Besides, the oregano essential oil included in the diet can have improved health status of farmed sea bream due to the high content of phenolic compounds that have potential protective effects against diseases. Previous studies showed that essential oil compounds of oregano or thyme may result in enhanced fish health status, growth performance, and/or disease resistance [20-22]. It has been ascertained that oregano contains carvacrol which is able to destroy the membrane of Gramnegative bacteria by releasing lipopolysaccharides as reported in the literature [23].

\section{Conclusion}

The management of the health status of sea bream is a fundamental issue in aquaculture. The transmission of pathogens, often associated with overcrowding, which increases the risk of infection, is often the cause of huge economic loss. Antibiotics and various other healthcare products can no longer be the solution. The increase in the prevalence of antibiotic resistance is a worldwide problem. Furthermore, certain antimicrobials are now forbidden for animal use and are, in any case, incompatible with an organic production system. Improving rearing strategies by means of good practices can mitigate stress factors and reduce the impact on the ecosystem. The implementation of biosecurity measures has confirmed the reduction of the risk of disease [24]. In the current paper, the larger market size of gilthead sea bream exhibited a higher omega- 3 fatty acids content compared to the regular size, ascertaining that producing seafood with beneficial properties is possible under a strict regimen of $\mathrm{ABF}$ prescription. To this purpose, our study focused on the optimization of the farming techniques for gilthead sea bream without the use of antibiotics, in the assumption that a condition of well-being implies an enhanced immune capacity, with subsequent benefits, not only in terms of the environment, but also for product quality. Furthermore, particular attention to this seafood product has highlighted the differences between market sizes. The omega- 3 fatty acid content was observed to be higher in larger size at an earlier stage than in those fed on conventional farms [25].

\section{Data Availability}

The data related to the manuscript concerning proximate composition and fatty acid profile of different groups of fish fillets are available from the corresponding author upon request.

\section{Conflicts of Interest}

The authors declare that there are no conflicts of interest regarding the publication of this paper.

\section{Acknowledgments}

This research was supported by EUREKA Project 2015 "A scientific contribution towards sustainable aquaculture". A particular thank goes to the team of Almarina for the precious collaboration provided during the fish samplings.

\section{References}

[1] S. Yilmaz, "Effects of dietary blackberry syrup supplement on growth performance, antioxidant, and immunological responses, and resistance of Nile tilapia, Oreochromis niloticus to Plesiomonas shigelloides," Fish \& Shellfish Immunology, vol. 84, pp. 1125-1133, 2019.

[2] N. Akhter, B. Wu, A. M. Memon, and M. Mohsin, "Probiotics and prebiotics associated with aquaculture: a review," Fish \& Shellfish Immunology, vol. 45, no. 2, pp. 733-741, 2015.

[3] European Platform for the Responsible Use of Medicines in Animals (EPRUMA), "EPRUMA best-practice framework for the use of antibiotics in food-producing animals reaching for the next level," 2018, http://www.epruma.eu/.

[4] A. A. Al-Sagheer, H. K. Mahmoud, F. M. Reda, S. A. Mahgoub, and M. S. Ayyat, "Supplementation of diets for Oreochromis niloticus with essential oil extracts from lemongrass (Cymbopogon citratus) and geranium (Pelargonium graveolens) and effects on growth, intestinal microbiota, antioxidant and immune activities," Aquaculture Nutrition, vol. 24, no. 3, pp. 1006-1014, 2018.

[5] A. Brum, S. A. Pereira, M. S. Owatari et al., "Effect of dietary essential oils of clove basil and ginger on Nile tilapia (Oreochromis niloticus ) following challenge with Streptococcus agalactiae," Aquaculture, vol. 468, no. 1, pp. 235-243, 2017.

[6] A. Hassoun and Ö. Emir Çoban, "Essential oils for antimicrobial and antioxidant applications in fish and other seafood products," Trends in Food Science \& Technology, vol. 68, pp. 26-36, 2017.

[7] S. Yilmaz, S. Ergün, and M. Yıgıt, "Effects of dietary FARMARIN ${ }^{\circledR}$ XP supplement on immunological responses and disease resistance of rainbow trout (Oncorhynchus mykiss)," Aquaculture, vol. 496, pp. 211-220, 2018.

[8] Association of Official Analytical Chemist, Official Methods of Analysis, Association of Official Analytical Chemist, Washington, DC, USA, 15th edition, 1990.

[9] J. Folch, M. Lees, and G. H. Sloane Stanley, "A simple method for the isolation and purification of total lipids from animal tissues," Journal of Biological Chemistry, vol. 226, no. 1, pp. 497-509, 1957.

[10] S. W. Christopherson and R. L. Glass, "Preparation of milk fat methyl esters by alcoholysis in an essentially nonalcoholic solution," Journal of Dairy Science, vol. 52, no. 8, pp. 1289-1290, 1969.

[11] IBM Corporation, IBM SPSS Statistics for Windows, Version 25.0, IBM Corporation, Armonk, NY, USA, 2017.

[12] G. Bernabè, "Rearing bass and gilthead bream," in Aquaculture, G. Barnabè, Ed., vol. 2, pp. 647-686, Ellis Horwood Limited, New York, NY, USA, 1990.

[13] C. Rodríguez, C. Acosta, P. Badía, J. R. Cejas, F. J. Santamaría, and A. Lorenzo, "Assessment of lipid and essential fatty acids requirements of black seabream (Spondyliosoma cantharus) by comparison of lipid composition in muscle and liver of wild and captive adult fish," Comparative Biochemistry and Physiology Part B: Biochemistry and Molecular Biology, vol. 139, no. 4, pp. 619-629, 2004.

[14] D. Menoyo, M. S. Izquierdo, L. Robaina, R. Ginés, C. J. LopezBote, and J. M. Bautista, "Adaptation of lipid metabolism, tissue composition and flesh quality in gilthead sea bream (Sparus aurata) to the replacement of dietary fish oil by 
linseed and soyabean oils," British Journal of Nutrition, vol. 92, no. 1, pp. 41-52, 2004.

[15] E. Tibaldi, G. Chini Zittelli, G. Parisi et al., "Growth performance and quality traits of European sea bass (D. labrax) fed diets including increasing levels of freeze-dried Isochrysis sp. (T-ISO) biomass as a source of protein and n-3 long chain PUFA in partial substitution of fish derivatives," Aquaculture, vol. 440, pp. 60-68, 2015.

[16] C. Nasopoulou and I. Zabetakis, "Benefits of fish oil replacement by plant originated oils in compounded fish feeds. A review," Lebensmittel-Wissenschaft \& Technologie, vol. 47, no. 2, pp. 217-224, 2012.

[17] P. Di Marco, T. Petochi, G. Marino et al., "Insights into organic farming of European sea bass Dicentrarchus labrax and gilthead sea bream Sparus aurata through the assessment of environmental impact, growth performance, fish welfare and product quality," Aquaculture, vol. 471, pp. 92-105, 2017.

[18] J. E. Breck, "Body composition in fishes: body size matters," Aquaculture, vol. 433, pp. 40-49, 2014.

[19] D. G. Fitzgerald, J. L. Forney, L. G. Rudstam, B. J. Irwin, and A. J. VanDeValk, "Gizzard shad put a freeze on winter mortality of age-0 yellow perch but not white perch," Ecological Applications, vol. 16, no. 4, pp. 1487-1501, 2006.

[20] E. Ahmadifar, B. Falahatkar, and R. Akrami, "Effects of dietary thymol-carvacrol on growth performance, hematological parameters and tissue composition of juvenile rainbow trout, Oncorhynchus mykiss," Journal of Applied Ichthyology, vol. 27, no. 4, pp. 1057-1060, 2011.

[21] D. Volpatti, B. Chiara, T. Francesca, and G. Marco, "Growth parameters, innate immune response and resistance to Listonella (Vibrio) anguillarum of Dicentrarchus labrax fed carvacrol supplemented diets," Aquaculture Research, vol. 45, no. 1, pp. 31-44, 2013.

[22] E. Yilmaz, S. Ergün, and S. ilmaz, "Influence of carvacrol on the growth performance, hematological, non-specific immune and serum biochemistry parameters in rainbow trout (Oncorhynchus mykiss)," Food and Nutrition Sciences, vol. 6, no. 5, pp. 523-531, 2015.

[23] M. E. Embuscado, "Spices and herbs: natural sources of antioxidants-a mini review," Journal of Functional Foods, vol. 18, pp. 811-819, 2015.

[24] P. J. G. Henriksson, A. Rico, M. Troell et al., "Unpacking factors influencing antimicrobial use in global aquaculture and their implication for management: a review from a systems perspective," Sustainability Science, vol. 13, no. 4, pp. 1105-1120, 2018.

[25] M. Sprague, J. R. Dick, and D. R. Tocher, "Impact of sustainable feeds on omega-3 long-chain fatty acid levels in farmed Atlantic salmon, 2006-2015," Scientific Reports, vol. 6, no. 1, article 21892, 2016. 


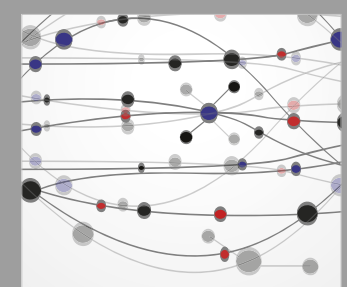

The Scientific World Journal
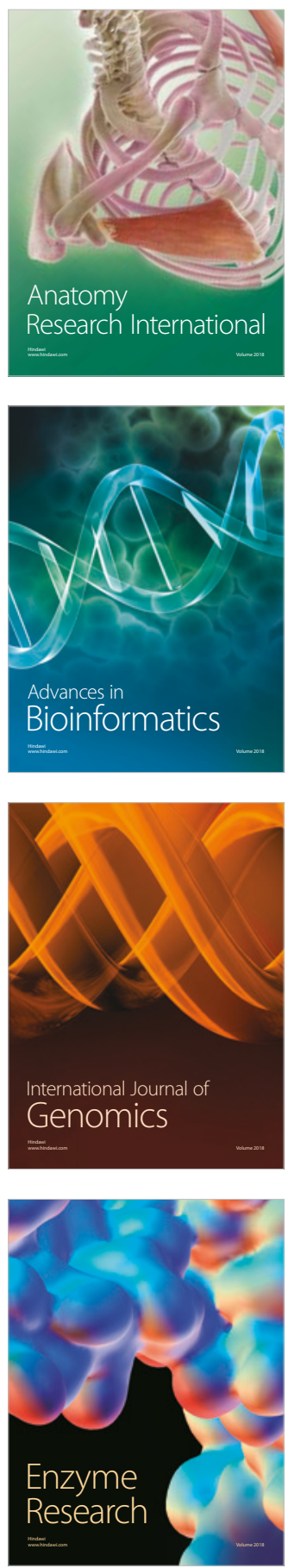
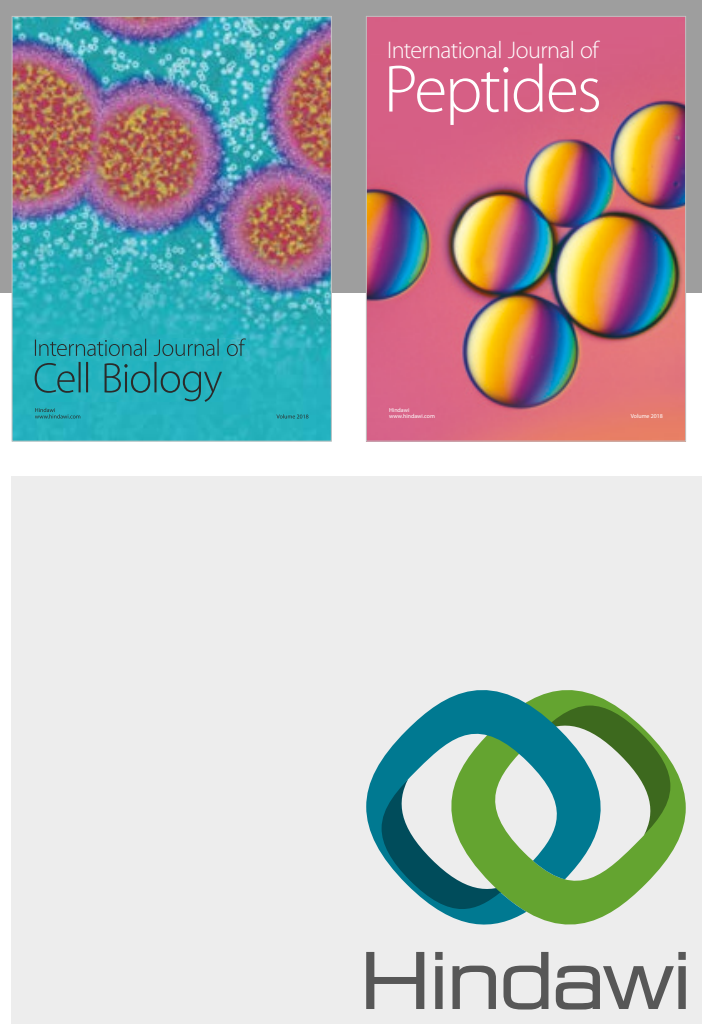

Submit your manuscripts at

www.hindawi.com
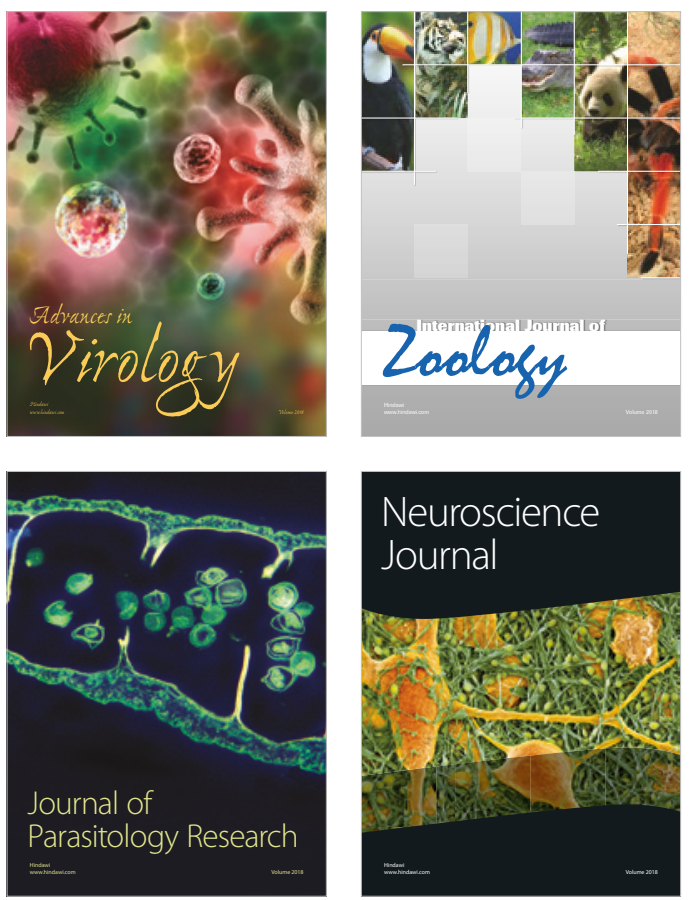
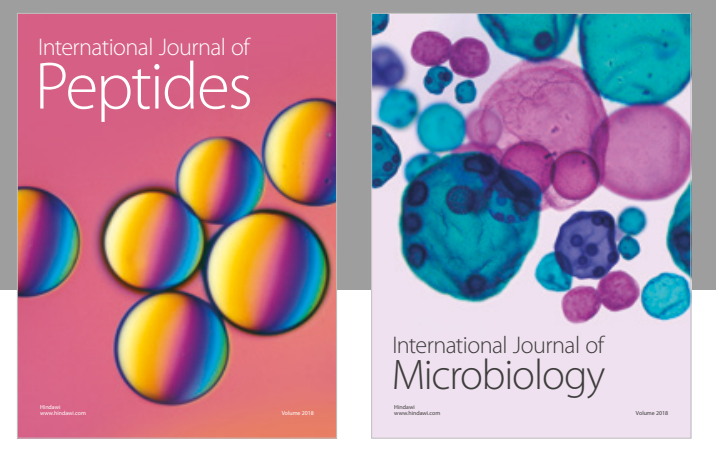

nternational Journal of Microbiology
Journal of
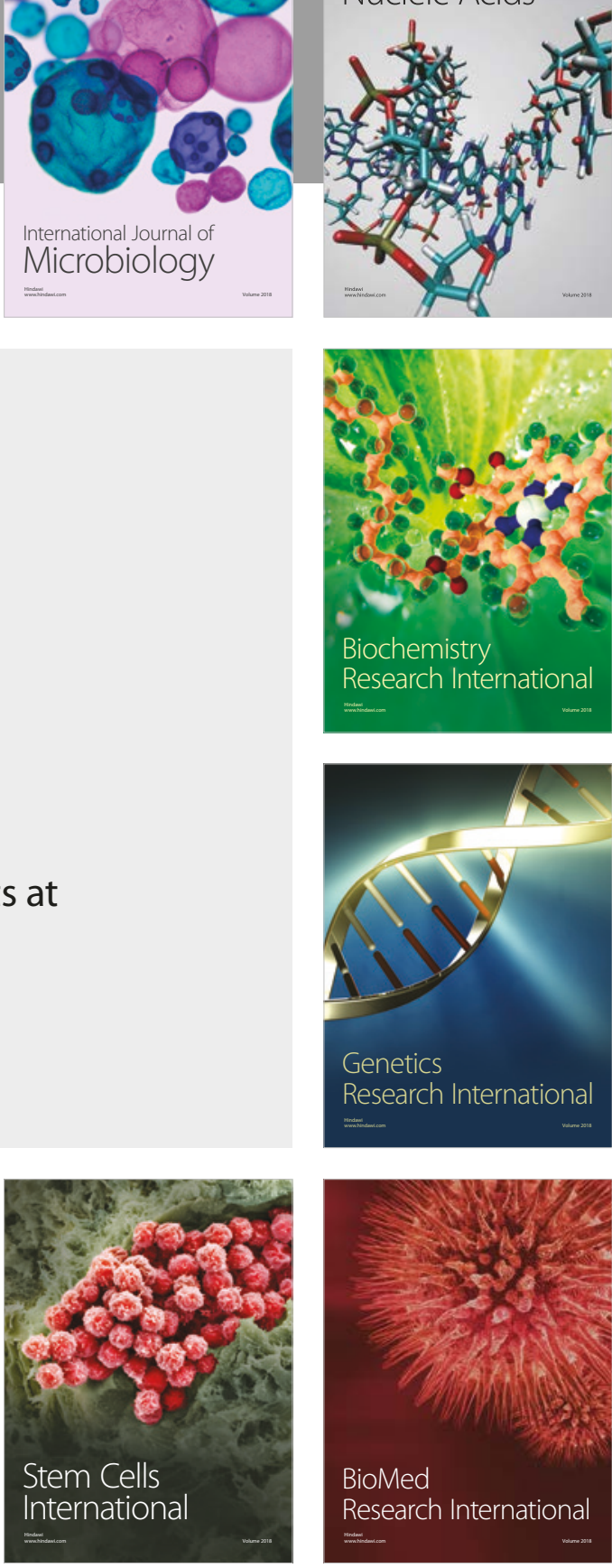
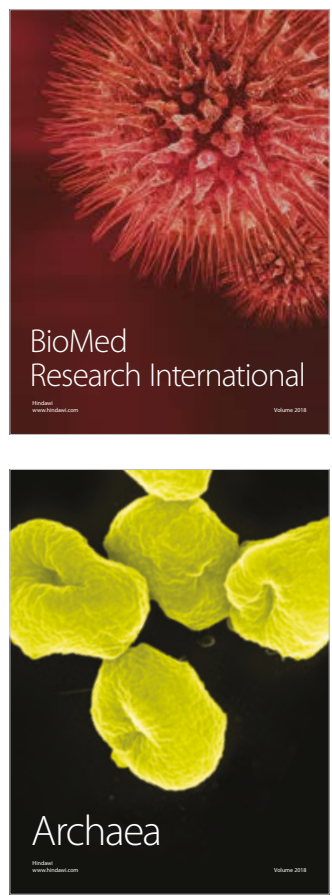